\title{
The geography of Internet adoption by independent retailers in the Netherlands
}

\author{
Jesse W J Weltevreden - \\ Netherlands Institute for Spatial Research (RPB), PO Box 30314, 2500GH The Hague, \\ The Netherlands; e-mail: jweltevreden@gmail.com
}

Oedzge A L C Atzema, Koen Frenken, Karlijn de Kruif §, Frank G van Oort \#

Section of Economic Geography, Urban and Regional Research Centre Utrecht (URU),

Faculty of Geosciences, Utrecht University, PO Box 80115, 3508 TC Utrecht, The Netherlands; e-mail: o.atzema@geo.uu.nl, k.frenken@geo.uu.nl, dekruif@procap.nl, oort@rpb.nl

Received 3 March 2006; in revised form 13 March 2007; published online 26 March 2008

\begin{abstract}
So far, the literature on Internet adoption by retailers has paid little attention to spatial variables. Using data on approximately 12000 independent retailers, we investigate the geographical diffusion of Internet strategies in the Netherlands. In particular, we examine to what extent Internet adoption differs among shopping centers, cities, and regions, while accounting for organizational variables. Results suggest that independent retailers at city and village centers are more likely to adopt information-only and online sales strategies than independents located at shopping centers at the bottom of the retail hierarchy. Furthermore, independent retailers in large(r) cities have a higher probability of adopting the Internet than their counterparts in small(er) cities. On the regional level, the likelihood of Internet adoption is higher for independent retailers in core regions than for independents in the periphery. Thus, geography seems to matter for Internet adoption by independent retailers.
\end{abstract}

\section{Introduction}

Business-to-consumer (b2c) e-commerce can be regarded as a disruptive innovation that, in the late 1990s, was reviewed as having the potential to make existing business models obsolete (Burt and Sparks, 2003; Wrigley et al, 2002). The history of retailing is replete with such innovations, such as the introduction of department stores and mail order. The rise of the Internet as a new channel for commerce provides threats to brick-and-mortar retailers. For example, in the Netherlands, the substitution of in-store shopping with online shopping by consumers has already caused some retailers to go bankrupt or to close some of their outlets (Weltevreden, 2007a). However, b2c e-commerce also provides opportunities for retailers - for instance, by developing a website retailers can enhance the relation with their customers by providing additional services, such as subscription to an e-mail newsletter. Furthermore, by engaging in online sales they can extend their market to areas in which they have no physical presence (Steinfield et al, 2001).

To date, there is a growing interest among geographers in the spatial distribution of online shoppers and the explanatory value of spatial variables for the adoption of online shopping by consumers (see, for example, Farag et al, 2006; 2007; Krizek et al, 2005; Ren and Kwan, 2006; Sinai and Waldfogel, 2004; Weltevreden, 2007a; Weltevreden and van Rietbergen, 2007). For the Netherlands, results indicate that consumers in urbanized areas are more likely to search and to buy online than

- Current address: BOVAG, PO Box 1100, 3980 DC Bunnik, The Netherlands.

$\S$ Current address: Procap, PO Box 3160, 3502GD Utrecht, The Netherlands.

\# Also: Netherlands Institute for Spatial Research (RPB), PO Box 30314, 2500GH The Hague, The Netherlands 
consumers in rural areas. Nevertheless, Dutch online shoppers in rural areas buy more frequently online than their counterparts in the more urbanized areas (Farag et al, 2006; Weltevreden, 2007a). Given the fact that the adoption of online shopping by consumers differs across urban settings it is reasonable to presume that the adoption of Internet strategies by retailers will differ in space as well. Understanding the diffusion patterns of b2c e-commerce adoption by consumers and retailers may provide insights into the spatial implications of this new form of commerce for shopping centers and urban form.

Despite a growing interest in the factors that determine the adoption of the Internet by retailers (Doherty and Ellis-Chadwick, 2006), few studies have investigated the explanatory value of spatial variables. Noticeable exceptions primarily focus on explaining differences in Internet strategy adoption among retailers at city centers (see, for example, Boschma and Weltevreden, forthcoming; Currah, 2002; Weltevreden and Atzema, 2006; Weltevreden et al, 2005). As such, systematic empirical research analyzing Internet adoption by retailers at different shopping locations and urban settings is virtually nonexistent.

In this paper we aim to fill this gap in knowledge by examining the geographical diffusion of website adoption among 11627 independent retailers ${ }^{(1)}$ in the Netherlands. While controlling for product and organizational variables, we investigate to what extent the adoption of a certain Internet strategy by independent retailers differs among shopping centers, cities, and regions. Three types of Internet strategies are distinguished: no website (pre-Internet strategy), an active website without online sales (informationonly strategy), and an active website with online sales (online sales strategies). For independent retailers with an active website, we also investigated the adoption time of a domain name.

The outline of this paper will be as follows. In section 2 a brief description of the Dutch retail context will be given so that the results presented in later sections can be contextualized whenever appropriate. Section 3 provides the theoretical underpinnings of our study. We turn to the data collection and methodology in section 4. Regression models testing our hypotheses are presented in section 5. We close with conclusions and directions for further research.

\section{The Dutch retail and transport context}

Compared with other high-income countries, such as France and Germany, the Netherlands has an 'old-fashioned' retail structure, characterized by a large number of small-scale shops per capita concentrated in urban areas, and only few large-scale hypermarkets and shopping malls at the edges of major cities (Evers, 2002). In the Netherlands, fully enclosed shopping malls have emerged mainly in city centers, similarly to within the UK, but to a lesser extent and at a smaller scale (Guy, 1994). Table 1 presents some figures on planned shopping centers to highlight the differences in retail structure between the Netherlands and other major European countries. As shown in this table, the Netherlands has the second highest gross leasable area per capita, but the smallest average shopping center size.

The exceptional retail structure in the Netherlands can be attributed to a restrictive retail planning policy for more than five decades, which prevented uncontrolled retail growth at the fringe of urban areas and protected traditional shopping centers and the

(1) In this paper only independent retailers with one outlet are included, as they are most influenced by their location as compared with multiple retailers. For the latter type of retailers the decision to develop a website is often taken at the headquarters and therefore is less influenced by local conditions. 
Table 1. Gross leasable area (GLA) of planned shopping centers (PSC) in European countries (2006). Sources: NRW (2006), Eurostat (2006).

\begin{tabular}{|c|c|c|c|c|c|}
\hline Country & $\begin{array}{l}\text { Total GLA } \\
\left(\mathrm{m}^{2}\right)\end{array}$ & PSCs & $\begin{array}{l}\text { Average size } \\
\text { of PSC }\left(\mathrm{m}^{2}\right)\end{array}$ & $\begin{array}{l}\text { Total population } \\
(\times 1000 \text { inhabitants })\end{array}$ & $\begin{array}{l}\text { Total GLA } \\
\text { of PSC per } \\
\text { per } 1000 \\
\text { inhabitants }\end{array}$ \\
\hline
\end{tabular}

\begin{tabular}{lccccc}
\hline United Kingdom & 13913161 & 648 & 21471 & 60393 & 230 \\
France & 13154680 & 609 & 21600 & 62886 & 209 \\
Germany & 11543364 & 472 & 24456 & 82438 & 140 \\
Spain & 8575138 & 421 & 20368 & 43758 & 196 \\
Italy & 8298621 & 525 & 15807 & 58752 & 141 \\
The Netherlands & $\mathbf{5 4 9 5 5 2 7}$ & $\mathbf{4 3 5}$ & $\mathbf{1 2 6 3 3}$ & $\mathbf{1 6 3 3 4}$ & $\mathbf{3 3 6}$ \\
Poland & 4275216 & 197 & 21702 & 38157 & 112 \\
Norway & 3658998 & 216 & 16940 & 4640 & 789 \\
Sweden & 3015452 & 201 & 15002 & 9048 & 273 \\
Austria & 2270500 & 129 & 17601 & 8266 & \\
& & & & &
\end{tabular}

functional retail hierarchy (Evers, 2002). City and village centers are, therefore, still at the top of the retail hierarchy in the Netherlands. The recent deregulation and decentralization of retail planning policy in the Netherlands is unlikely to result in a more relaxed policy, as the new provincial guidelines are largely consistent with the previous national guidelines concerning peripheral retailing (Spierings, 2006).

It should also be remembered that the Netherlands is a small and highly urbanized country in which, even in rural areas, consumers have a relatively good shop accessibility in comparison with larger countries such as Germany, Canada, or the US. As a result, the Netherlands differs from other West European countries and the US in terms of the share of total distance that is covered by slow transportation modes. In 1990 the share of walking and cycling in the total distance traveled was 12\% for the Netherlands, compared with $4 \%$ for Western Europe as a whole (Schwanen et al, 2004). Of all shopping trips in the Netherlands more than half are made on foot or by bicycle. Together, these modes account for $20 \%$ of all kilometers traveled for shopping purposes (Dieleman et al, 2002). The outcomes of this paper thus should be interpreted with the Dutch retail and transport context in mind, though the conceptual framework and research methodology can be applied to any country or region.

\section{Theoretical framework}

Like any other innovation, the adoption of Internet strategies by independent retailers can be considered as a diffusion process that takes place in space and time. When studying this adoption process from a geographical perspective, several spatial logics are expected to operate simultaneously: (1) a shopping center hierarchy differentiating between shopping locations within cities, (2) an urban hierarchy differentiating between different cities, and (3) a regional hierarchy to distinguish between more densely urbanized and rural regions.

\subsection{Shopping center hierarchy}

An important part of retail location theory is based on the central-place theory of Christaller (1933). In this theory, goods are classified in terms of thresholds - that is, the population necessary to make the supply of a good profitable. The highest threshold goods are, therefore, only available in the largest urban centers, while low-threshold goods are traded locally. Since the catchment area for lower order goods is considerably smaller than for higher order goods, a hierarchy of shopping centers emerges with 
a few central places supplying the whole range of goods surrounded by larger numbers of towns and villages offering smaller product ranges.

Berry (1967) applied the central-place concept of Christaller to intraurban shopping locations resulting in an urban shopping center hierarchy. Berry defined five categories, ranging from the convenience center with the lowest catchment area to the metropolitan central business district with a regional or national function. Higher order centers encompass large numbers of retail outlets and specialized shops, while the lowest order centers are only important for the provision of daily goods to the surrounding population of those centers. A previous study found that Berry's retail hierarchy also applied to the Netherlands, though with city centers at the top of the retail hierarchy (Borchert, 1998).

Internet penetration is expected to be lowest in shopping centers at the bottom of the retail hierarchy, since they mainly retail daily goods that are less suitable for b2c commerce. However, after accounting for the type of product, we still expect independent retailers in these localities to show lower levels of adoption than independents in higher order centers for two reasons. First, higher order centers, such as city and village centers, have larger catchment areas, and thus serve large numbers of consumers of which the majority do not reside in the vicinity of the center. As the Internet provides a medium to communicate over any distance and at relatively low costs, retailers with many distant and dispersed customers will have a higher payoff from adopting the Internet. Second, the position of a shopping center in the hierarchy strongly correlates with the size of the location. Higher order centers generally contain more retail outlets than lower order centers. Assuming that retailers within the same shopping area are part of a communication network, or are able to learn by imitation (see Boschma and Weltevreden, forthcoming), an innovation will spread faster in higher order centers than in lower order centers.

Hypothesis 1a. Independent retailers in shopping centers at the top of the retail hierarchy adopted the Internet earlier than their counterparts located in shopping centers at the bottom of the retail hierarchy.

Hypothesis 1 b. Independent retailers in shopping centers at the top of the retail hierarchy are more likely to adopt information-only and online sales strategies than their counterparts located in shopping centers at the bottom of the retail hierarchy.

Note here that specialized (eg factory outlet centers) and large-scale retail locations (eg furniture districts) fall outside the hierarchical shopping center classification. Like city and village centers, the specialized and large-scale retail locations have large catchment areas. For example, consumers are willing to travel large distances to visit a furniture district. For these localities the Internet may also be an excellent tool to reach (potential) customers residing far from the shopping center in an easy and inexpensive way. Therefore, we assume that independent retailers at these localities have the same likelihood to adopt the Internet as their counterparts at city and village centers.

Furthermore, there is a considerable number of retailers that are not located in a shopping center in the Netherlands, also referred to as solitary retailers. These retailers do not experience the advantages of retail clustering in a shopping center (eg high footfall). Instead, they need other means to attract customers. For solitary retailers the payoff to adopt the Internet is expected to be high, as the Internet provides the possibility of market extension and of informing potential customers (Steinfield et al, 2001). As such, we expect that:

Hypothesis 2a. Solitary independent retailers and independents at large scale/special retail locations adopted the Internet as early as their counterparts at city and village centers. 
Hypothesis $2 \boldsymbol{b}$. Solitary independent retailers and independents at large scale/periphery retail locations are as likely to adopt information-only and online sales strategies as their counterparts at city and village centers.

\subsection{Urban hierarchy}

According to the urban density hypothesis retailers in large(r) cities have a higher likelihood to follow an Internet strategy, as the adoption costs decrease when population size and density increase (Foreman et al, 2005a; 2005b). There are various reasons why these adoption costs are lower in large(r) cities. First, large(r) cities usually have a more advanced telecommunication infrastructure (eg broadband and fiberglass networks) which stimulates Internet adoption (Foreman et al, 2005a; 2005b; Kolko, 2000). Second, large(r) cities contain a larger pool of specialistssuch as web designers and other computer specialists - that retailers can hire to develop a website (Foreman et al, 2005a; 2005b; Kolko, 2000; Moss, 1998). Third, innovations diffuse faster in large(r) cities, because of a higher probability of knowledge spillovers and imitation of successful strategies (Boschma and Weltevreden, forthcoming; Brown, 1981; Foreman et al, 2005a; 2005b; Kolko, 2000; Pred, 1977). Finally, the adoption of Internet strategies is influenced by local consumer demand (Anderson et al, 2003; Boschma and Weltevreden, forthcoming). Consumers in large(r) cities have a higher probability to engage in online shopping as they are better educated, have higher incomes, and are more time-constrained; thus having a lifestyle that stimulates them to shop online (Anderson et al, 2003; Kolko, 2000). To summarize:

Hypothesis 3a. The larger the city in which an independent retailer is located, the earlier it adopted the Internet.

Hypothesis $\mathbf{3 b}$. The larger the city in which an independent retailer is located, the higher the probability of adoption of information-only and online sales strategies.

\subsection{Regional hierarchy}

Internet adoption is not only expected to vary among cities of different size, but also among densely populated areas [regions with many (large) cities] and peripheral areas (regions with few cities). Agglomeration economies responsible for the hierarchical diffusion of Internet adoption from large to small settlements apply to the regional level as well. According to the filtering-down theory, innovations are consecutively established at lower levels in the regional hierarchy (Thompson, 1968). The filteringdown theory is based upon the notion of an urban product life cycle, with new innovations starting in metropolitan areas and moving to rural areas when the innovation matures. The speed of regional diffusion is determined by the speeds by which the fixed setup costs of innovation decline and the regional demand for the innovation increases. Thus, following Thompson, at the regional level a geographical diffusion pattern from core regions to peripheral regions is likely to occur. Nonetheless, the core regions retain their first-mover advantage relative to the other regions.

Hypothesis 4a. The higher the urban density of the region in which a shop is located, the earlier it adopts the Internet.

Hypothesis $\mathbf{4 b}$. The higher the urban density of the region in which a shop is located, the higher the probability of adoption of information-only and online sales strategies.

Yet, for certain types of goods hypotheses $4 \mathrm{a}$ and $4 \mathrm{~b}$ are not expected to hold. What is specific for Internet adoption-in the form on online sales-is that additional logistic costs are involved in the distribution of purchased goods to the consumer, and that these costs vary for different types of goods. In this context, 
the distinction between core urbanized regions and peripheral rural regions is also of importance. Consumers in peripheral locations have the highest benefits from access to the wide variety of goods provided via the Internet, because they need to travel larger distances for the purchase of goods (Anderson et al, 2003; Farag et al, 2006; Sinai and Waldfogel, 2004; Weltevreden, 2007a). They can use the Internet to overcome isolation from high-quality retail locations. This argument, however, mainly applies for goods that can be easily delivered by mail (eg books and CDs) or parcel services (eg cosmetics and clothes), since the delivery costs of mail and packages are independent of the distance in most countries (including the Netherlands). A previous study showed that the probability of buying CDs, videos, and DVDs via the Internet is higher for Dutch consumers with a relatively bad accessibility to shops (Farag et al, 2006). Retailers selling 'mail and parcel goods' in peripheral regions may, thus, be more inclined to engage in online sales than their counterparts in core areas to better service their more dispersed customers.

By contrast, for 'freight goods' that cannot be distributed by mail and parcel services (eg groceries and furniture), retailers in core areas may be more likely to engage in online selling. To be profitable in terms of logistics, online grocery retailers, for example, must have a high density of customers (Murphy, 2003; Visser and Lanzendorf, 2004). To summarize, the likelihood of engaging in online sales will differ between core and peripheral regions, depending on the type of good that is transported:

Hypothesis 5a. Independent retailers in the periphery that sell 'mail and parcel goods' are more likely to adopt an online sales strategy than their counterparts in the core area.

Hypothesis $\mathbf{5 b}$. Independent retailers located in the core region that sell 'freight goods' are more likely to adopt an online sales strategy than their counterparts in the periphery.

\subsection{Control variables: product and size}

The adoption of Internet strategies by retailers largely depends on the characteristics of their product and their organization (size). As such, one needs to account for these firm characteristics when studying the geographical diffusion of Internet strategies. Otherwise, composition effects of retail locations may distort the empirical results.

Internet adoption varies among retailers of different products because consumers' shopping efforts vary with respect to the type of product (Klein, 1998; Peterson et al, 1997). Search-goods sectors - such as books, videos and DVDs, and CDs - are among the most popular products bought online by Dutch consumers (Weltevreden, 2007b). Not surprisingly, search-good retailers have a high likelihood to adopt an informationonly and even more so an online sales strategy, as compared with retailers selling experience or convenience goods (Boschma and Weltevreden, forthcoming; EllisChadwick et al, 2002; Weltevreden and Atzema, 2006; Weltevreden et al, 2005). Since experience goods require more physical evaluation by consumers and often come in collections that change regularly (eg clothing), retailers selling these kind of products are less likely to sell online. The same holds for convenience-goods (ie daily items, such as groceries and personal care items) retailers, as these items are frequently purchased and are part of consumers' daily routines. It takes more effort to acquire information about those products online than a daily trip to a neighborhood or convenience center. As such, experience-goods and convenience-goods retailers are more likely to follow an information-only strategy (Boschma and Weltevreden, forthcoming; Weltevreden and Atzema, 2006; Weltevreden et al, 2005).

Internet adoption of retailers is also influenced by the size of the retail organization. Larger firms have several advantages over smaller firms with regard to the adoption of technological innovations, such as the Internet. Compared with small 
firms, larger firms have a greater ability to raise capital, to bear the costs of the innovation, and to bear the risk of failure (Brown, 1981). Empirical studies show that large(r) retailers indeed have a higher probability to follow an Internet strategy, as compared with small(er) retailers (eg Ellis-Chadwick et al, 2002; Morganosky, 1997; Weltevreden and Atzema, 2006; Weltevreden et al, 2005; Worzala et al, 2002).

\section{Methodology}

\subsection{Data collection}

We used a subset of the 2004 retail location database of Locatus with data of all retail outlets in the Netherlands. The subset contains data about every independent retailer with one outlet in thirteen retail categories (11627 independents), representing $10.8 \%$ of all retail outlets of independent retailers in the Netherlands. The following variables are included in the dataset: name; address; formula; sector; floor space; and shopping center type (see table 2 for descriptive statistics).

Some remarks about Locatus's method of data collection should be made. Collecting retail data of every shopping location in the Netherlands is a time-consuming business, as employees of Locatus physically visit every shop. As such, Locatus attempts to update the data of each retail outlet at least once in every four years. However, many shopping locations are visited more frequently (once a year or more) as Locatus's customers demand accurate data. With respect to our dataset, $22.3 \%$ of the shops were last visited by Locatus in $2004,70.1 \%$ in $2003,6.1 \%$ in 2002 , and $1.6 \%$ in 2001. (2)

Through a time-consuming procedure (December 2004 to March 2005), we searched for the websites of the independent retailers in our dataset via Google. (3) Despite the fact that Google is the most accepted and used search engine-searching through more than 8 billion web pages worldwide - it is not able to find all websites one is looking for. A study conducted in Germany revealed that Google was only able to find $61 \%$ of all 'de domains' (Heise Online, 2004). To improve the accuracy of the data, we also searched directly for websites by typing likely domain names in the address bar of the browser. We argued that retailers largely choose domain names that are closely related with their company name. In some cases this strategy resulted in 'hits' that we could not find via Google. To further improve the accuracy, the data were reexamined by three trained coders. After we obtained the web addresses, we made use of the Whois database on the Internet to find the registration date of each domain name.

\subsection{Dependent variables}

We use two dependent variables to investigate the geographical diffusion of retail Internet adoption. First, we use the date of domain name registration as proxy for the adoption time of independent retailers. This analysis is an innovation diffusion analysis as the dependent variable measures the number of days that independents have had a domain name (table 2). Note that independent retailers without an active website have been left out of this analysis. Many of them do not have a domain name, while in the cases of those that have one, we could not trace it without an active web address. This analysis, however, does not give insight in the type of Internet strategy independents follow.

(2) We were able to investigate the accuracy of this dataset by comparing it with our own dataset that consists of data on every retail outlet in eight Dutch city centers which were collected in 2003-04 (see Weltevreden and Atzema, 2006). The Locatus data turned out to be highly accurate, at least for those eight city centers.

(3) The fact that it takes much time to gather data on Internet strategies of retailers is the main reason for using a subset of the retail location database of Locatus. From this database we selected thirteen retail categories that vary in terms of prospects for e-commerce (see table 4). 
Table 2. Descriptive statistics.

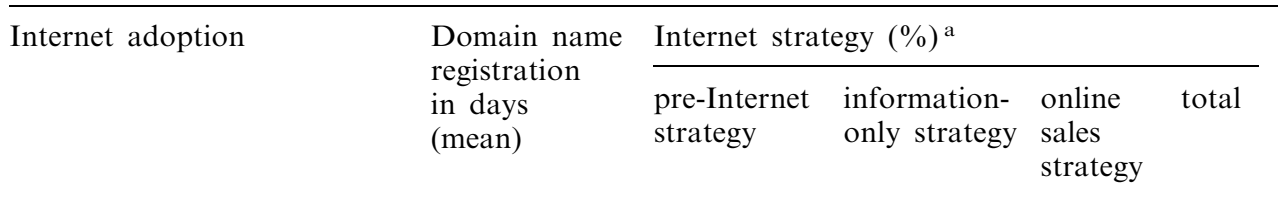

(dependent)

Domain registration in days 1600

No website

Information-only strategy $\quad 1565$

Online sales strategy 1762

$\begin{array}{rrrrr}- & 100 & 0 & 0 & 70 \\ 1565 & 0 & 100 & 0 & 24 \\ 1762 & 0 & 0 & 100 & 5\end{array}$

Shopping center hierarchy

Small neighborhood/

1603

convenience centers

City district/large neighborhood centers

City/village centers $\quad 1574$

Solitary urban locations $\quad 1627$

Peripheral/large-scale retail 1721

68
locations

Urban hierarchy

Small-sized cities

Medium-sized cities

Large-sized cities

1567

1589

1705

Regional hierarchy

Periphery

Intermediary

Core (Randstad)

Retail category

Supermarkets

Delicatessen stores

Drug stores

Perfume and cosmetics stores

Ladies-wear stores

Family-wear stores

Men's fashion stores

Sport shops

Furniture stores

Toy stores

Computer stores

Book stores

CD shops

Size

Log (floor space) $\left(\mathrm{m}^{2}\right)$

Valid $N$

$0.095^{\mathrm{b}}$

3334

1559

1596

1644

72

74

23

21

72

68
54

23

26

41

72

69

70

24

25

24

73

69

69

1459

1346

1528

1474

1334

1595

1585

1531

1571

1451

1899

1759

1670

87

60

89

73

87

79

69

60

57

56

25

48

60

$\begin{array}{lll}23 & 5 & 37 \\ 26 & 5 & 31 \\ 24 & 6 & 32\end{array}$

${ }^{a}$ Percentages may not add up to $100 \%$ due to rounding.

${ }^{\mathrm{b}}$ Pearson correlation coefficient, significant at $p<0.01$.

${ }^{\mathrm{c}}$ Mean of $\log$ (floor space). 
Therefore, we also distinguish three types of Internet strategies that independents adopted at a particular moment in time (early 2005): (1) a pre-Internet strategy (no website), (2) an information-only strategy (a website, but without online sales), and (3) an online sales strategy (see table 2). As some retailers have more than one website, we decided to include the most sophisticated one in our analyses. Independent retailers that have a website 'under construction' were considered to have an information only strategy, while independents that have an empty domain name were not considered to have an informative website. Furthermore, we speak of an online strategy when consumers can order products via the website. The payment need not necessarily be conducted online. By looking at these two dependent variables we are not only able to investigate which independent retailers at which locations were the first on the Internet, but also to what extent they use the new commercial possibilities as provided by the Internet.

\subsection{Independent variables}

As independent variables we use three spatial variables: (1) a shopping center hierarchy, (2) an urban hierarchy, and (3) a regional hierarchy. In addition, we use two control variables: product and size.

First, the typology of shopping centers was also already present in our dataset (see table 3). ${ }^{(4)}$ Besides the shopping centers presented in this table, solitary urban retailers, solitary retailers at business parks, and solitary peripheral retailers are also distinguished. To have sufficient numbers of cases in each category, some shopping locations

Table 3. A typology of shopping centers [source: adapted from Locatus (2004)].

Type Definition

City/village center

City district

Large neighborhood center

Small neighborhood center

Convenience center

Large-scale retail location

Special shopping center

Solitary shop
The largest and central shopping location in a city or village (five stores or more).

A shopping center with more than fifty stores operating next to a large city center (ie a hundred stores or more).

A shopping center with between twenty-five and fifty stores operating next to a city or village center.

A shopping center with between ten and twenty-five stores, or a center with five to ten stores and two or more supermarkets operating next to a city or village center (and city districts/large neighborhood centers).

A shopping center with five to ten stores and one or no supermarket operating next to a city or village center (and city districts/neighborhood centers).

A shopping center with five or more stores, with a mean floor space of $500 \mathrm{~m}^{2}$ or more per shop. The sectors 'pets, flowers and plants', 'consumer electronics', 'bikes and car accessories', 'do-it-yourself', and 'furniture and home furnishing' must make up at least $50 \%$ of the total floor space in these centers.

A shopping center that does not belong to one of the other categories (eg factory outlet centers, shopping centers at airports).

A shop that is not located in one of the preceding shopping centers.

(4) Note that city and village centers can be very small (five to fifty stores in villages) or very large (more than 400 stores, for example, in Amsterdam) and that other levels in the shopping center hierarchy are only present at a certain urban size. 


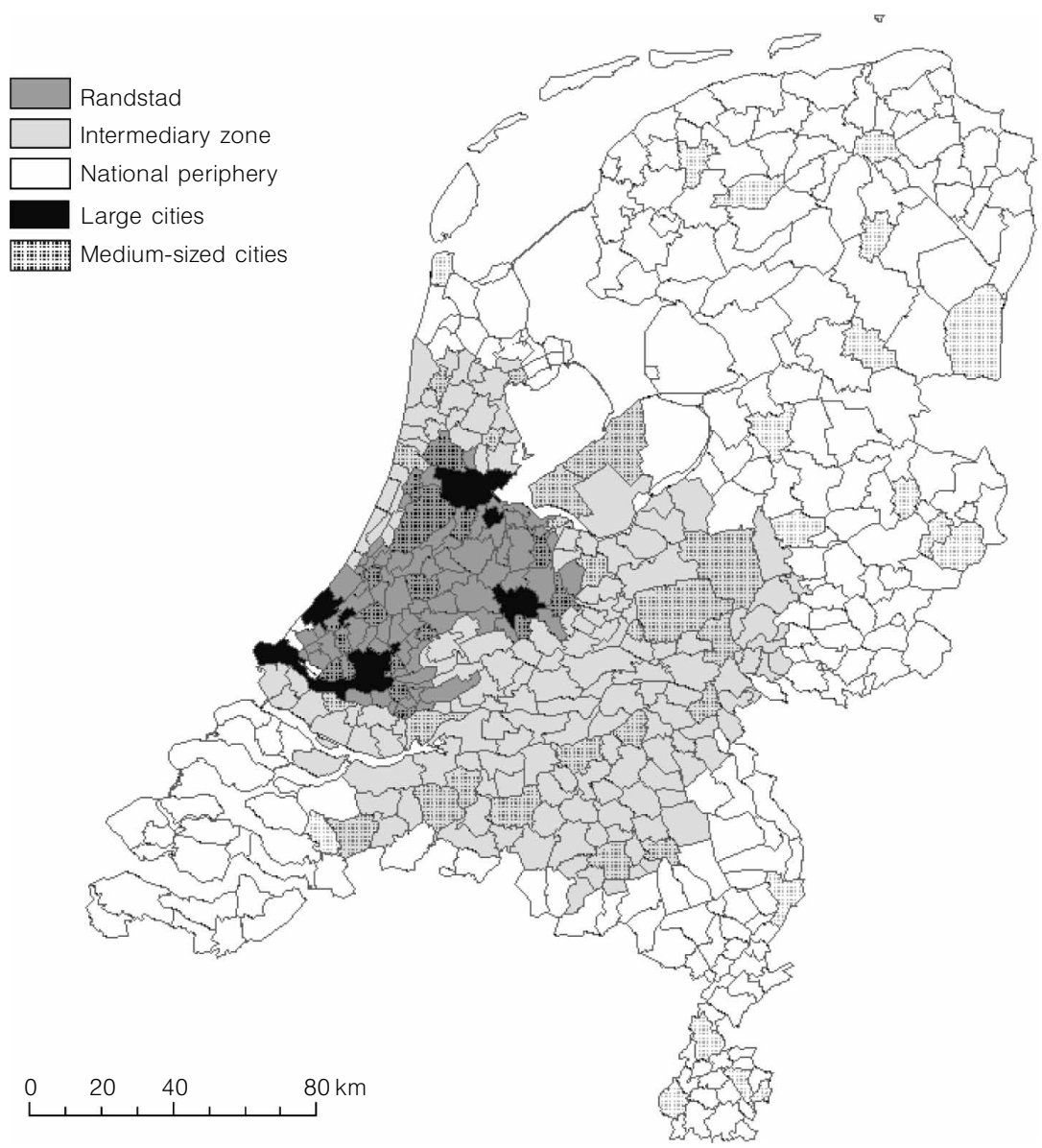

Figure 1. Urbanization map of the Netherlands, including the core region (Randstad), the surrounding intermediary zone, and the periphery.

were put together. We combined city district centers with large neighborhood centers, and combined small neighborhood centers with convenience centers. Furthermore, solitary retailers at business parks, solitary peripheral retailers, and special shopping centers were combined with peripheral or large-scale retail locations, resulting in the shopping center typology as presented in table 3 .

Second, within the urban hierarchy three levels are distinguished, depending on the number of inhabitants (in 1996) of the municipality in which the independent retailer is located: large cities $(>200000)$, medium-sized cities $(45000-200000)$, and small-sized cities $(<45000)$ (see figure 1). Using this definition, there are only four large cities in the Netherlands: Amsterdam, Rotterdam, The Hague, and Utrecht.

Third, at the regional level one can make a distinction between the most urbanized parts of the Netherlands, also known as the Randstad, and more rural parts (the periphery). Since the 1950s the Randstad has expanded southwards and eastwards to surrounding regions. On the base of employment gravity values, we made a distinction between the core region (the Randstad), the surrounding intermediary zone, and the periphery (van Oort, 2004), which we will use in our analysis (see figure 1).

Fourth, we apply a sector classification and a product typology. The first distinguishes among thirteen retail categories (see table 4) and includes convenience goods, 
Table 4. Sectors differentiated by product characteristics and logistic intensity.

\begin{tabular}{lcll}
\hline Product type & Mail & Parcel & Freight \\
\hline Convenience goods & - & $\begin{array}{c}\text { Drug stores, Perfume and } \\
\text { cosmetics } \\
\text { Ladies wear, family wear, } \\
\text { mens' wear, sport shops }\end{array}$ & $\begin{array}{c}\text { Supermarkets, } \\
\text { delicatessen } \\
\text { Furniture }\end{array}$ \\
Search goods & Books, CDs & Computers, toy stores & - \\
\hline
\end{tabular}

search goods, and experience goods. ${ }^{(5)}$ To test our two specific hypotheses (5a and $5 \mathrm{~b}$ ) concerning regional differences in online sales adoption, we also use a product typology, which deals with the logistic intensity (ie delivery costs) of products: (1) mail goods (low cost, independent of distance), (2) parcel goods (medium cost, independent of distance), and (3) freight goods (high cost, dependent on distance). We assigned our thirteen retail categories to one of those three product types (see table 4).

Fifth, we use a measurement for the size of independent retailers. Recall that all independents in our sample have only one outlet. As such, we use the floor space of independent retailers (measured in $\mathrm{m}^{2}$ ) as a size indicator. This variable was already present in the original dataset, and is a good proxy for the size of the organization. In the analyses we use the logarithm of floor space as it led to a better model fit.

\section{Results}

\subsection{Domain name diffusion in the Netherlands (1994-2005)}

In figure 2 four maps are displayed that show the geographical distribution of domain name registration in the Netherlands for the period 1994-2005. The black dots on the maps represent new adopters in a specific year, while the grey dots represent independent retailers that adopted a domain name in previous years.

In 1994 hardly any independent retailer had registered a domain name. Four years later (in 1998) - just before the Internet hype - domain registration became more popular, but was largely concentrated in the core region (Randstad) and in the large and medium-sized cities (compare figure 1 with figure 2). Between 1999 and 2002 the majority of the independents with a website in our sample registered a domain name. In this period domain name registration expanded to small cities and peripheral regions, while independents in the core region and large and medium-sized cities continued to register. Note that the majority of the (large) multiple retailers had already registered a domain name earlier (between 1995 and 1998) (Weltevreden, 2007a). In the final map (2004-05) the diffusion of domain registration slows down, with only a few adopters (mainly in the large and medium-sized cities).

\subsection{Multivariate results of domain name registration and Internet adoption}

In this section we present the estimation results for the joint effects of location, product, and organization on domain registration and Internet strategy adoption, respectively. Linear regression was chosen for domain registration, as it is a continuous variable that measures the number of days that independent retailers have had a domain name (see model 1 in table 5). ${ }^{(6)}$

(5) Convenience goods are frequently purchased items available at many locations. For experience goods it holds that information cannot be known without direct experience or is very costly, while for search goods this information can be obtained more easily (Copeland, 1923; Nelson, 1970).

(6) The reader should note that hazard modeling is more often used in innovation diffusion studies. However, our data do not permit hazard model estimation for two reasons. First, we do not have information about the characteristics of independent retailers at the time that they were first able to register a domain name - that is, 1994. Second, it is likely that a considerable number of retail businesses were founded after 1994. 

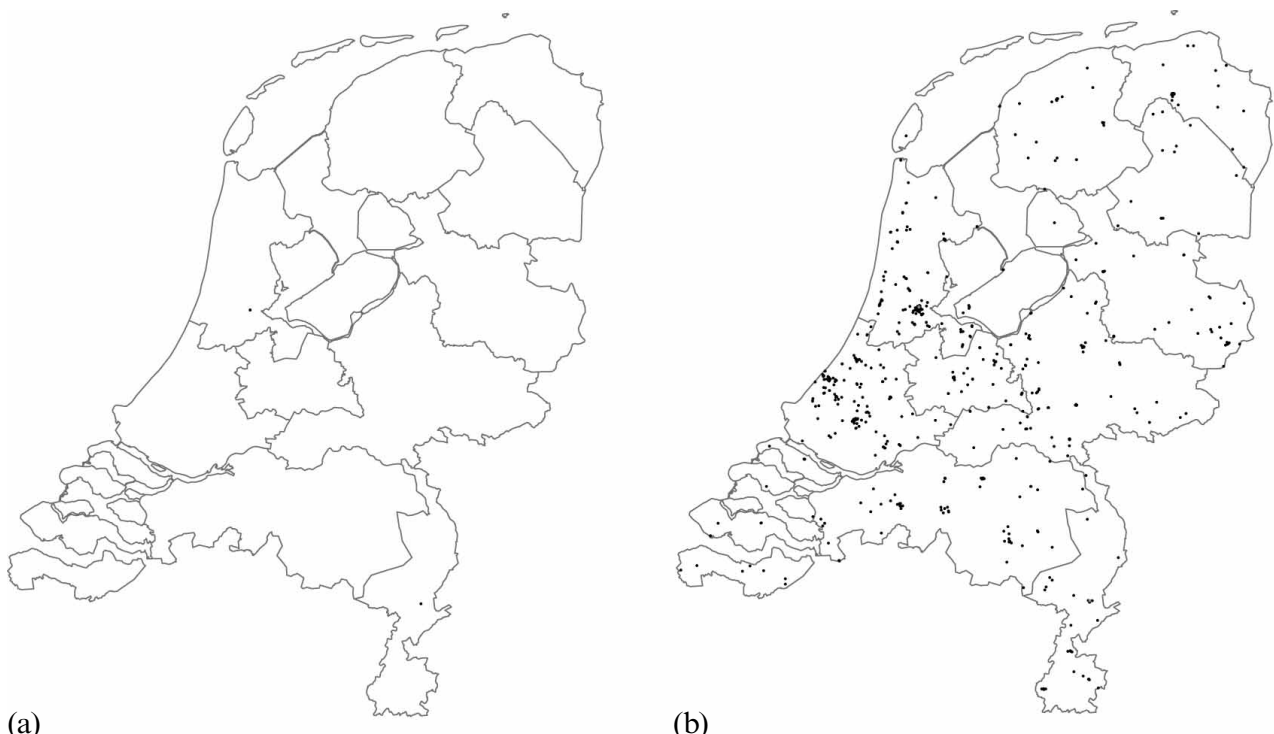

(a)

(b)

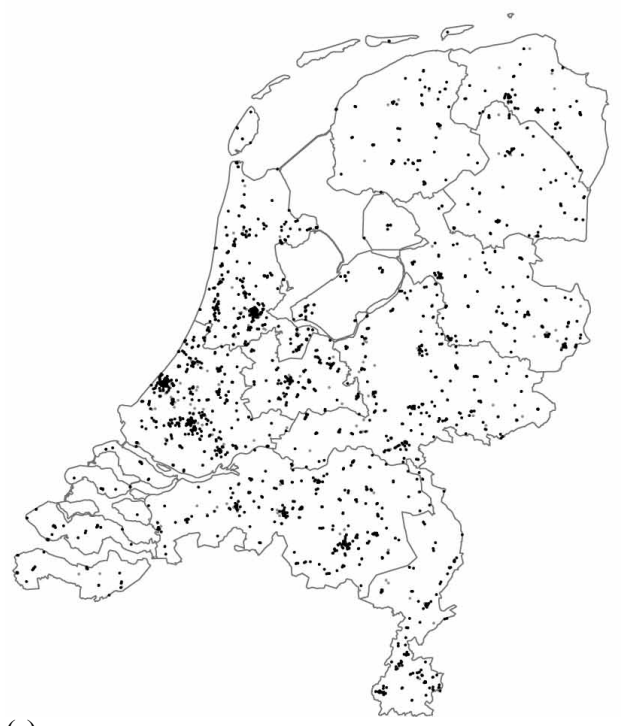

(c)

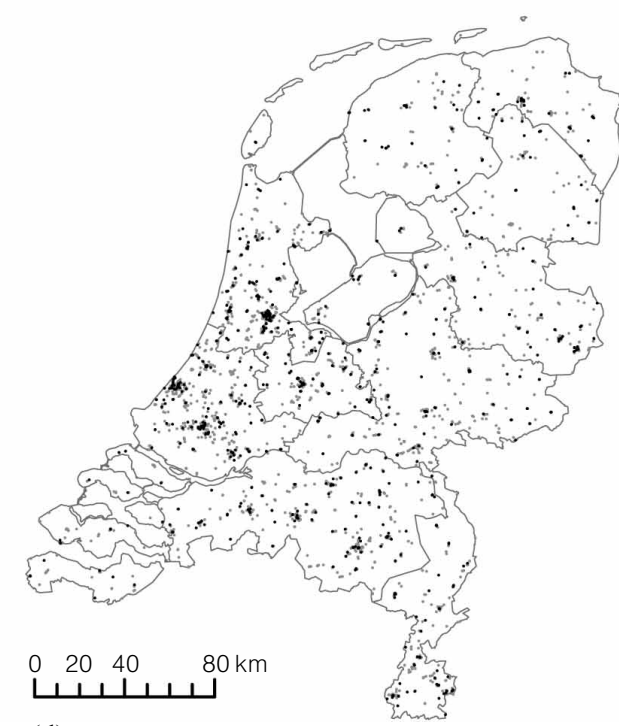

(d)

Figure 2. Geographical diffusion of domain name registration by independent retailers in the Netherlands (1994-2005): (a) 1994; (b) 1995-98; (c) 1999-2002; (d) 2003-05.

For Internet strategy adoption, we used multinomial logistic regression (see model 2 in table 5), as the dependent variable consists of more than two categories (ie pre-Internet strategy, information-only strategy, and online sales strategy). (7) The multinomial logistic regression model estimates the effect of the explanatory variables on the probability (differential odds) that one of three strategies will be selected (Wrigley, 1985). In our models we use the pre-Internet category as the baseline by

(7) We did not apply a nested model, because we consider the three alternatives to be independent. Many retailers have never used an information-only strategy before applying an online sales strategy (and vice versa). 
Table 5. Linear regression of domain registration and multinomial logistic regression of Internet strategy adoption.

Model 1

domain registration

(in days) $B(\mathrm{SE})$
Model 2 (reference category $=$ pre-Internet strategy)

information-only online sales strategy $B(\mathrm{SE}) \quad$ strategy $B(\mathrm{SE})$
Shopping center hierarchy

Small neighborhood/ convenience centers

City district/large neighborhood centers

City/village centers

Solitary urban locations

Peripheral/large-scale retail locations

Urban hierarchy

Small-sized cities

Medium-sized cities

Large-sized cities

Regional hierarchy

Periphery

Intermediary zone

Core (Randstad)

Retail category

Supermarkets

Delicatessen stores

Drug stores

Perfume and cosmetics stores

Ladies-wear stores

Family-wear stores

Men's fashion stores

Sport shops

Furniture stores

Toy stores

Computer stores

Book stores

CD shops

Size

Log (floor space) $\left(\mathrm{m}^{2}\right)$

Constant/intercept

$F$
$\chi^{2}$

$-2 \log$ likelihood intercept only

$-2 \log$ likelihood final

$R^{2}$

Adjusted $R^{2}$

Pseudo Nagelkerke $R^{2}$

N

$* p<0.10 ; * * p<0.05 ; * * * p<0.01$.

0

$$
-39.225
$$

56.897

57.510

$121.452 *$

$$
\text { (62.364) }-0.094
$$

$(0.125)$

0

$\begin{array}{llll}(53.300) & 0.223^{* *}(0.107) & 0.592 * * *(0.207) \\ (61.999) & 0.030 & (0.127) & 0.501 * *(0.237) \\ (62.404) & 0.321^{* *}(0.127) & 0.687 * * *(0.262)\end{array}$

0

$\begin{array}{cc}65.184 * * & (26.730) \\ 250.757 * * * & (45.486)\end{array}$

0

$0.142 * * *(0.054) \quad 0.487 * * *(0.107)$

$250.757 * * * \quad(45.486) \quad 0.212 * * \quad(0.095) \quad 0.459 * * *(0.176)$

\begin{tabular}{llllr}
\multicolumn{1}{c}{} & & 0 & 0 & \\
$53.375 *$ & $(28.911)$ & $0.207 * * *(0.057)$ & 0.074 & $(0.118)$ \\
$70.731 * *$ & $(36.050)$ & $0.277 * * *(0.074)$ & $0.451 * * *(0.142)$
\end{tabular}

$\begin{array}{lll}0 & & 0 \\ 132.433 & (134.491) & 1.895 * * *(0.234)\end{array}$

$285.270 * \quad(150.454) \quad 0.070 \quad(0.251) \quad 1.112 * \quad(0.580)$

$186.486 \quad(162.358) \quad 1.236^{* * *}(0.288) \quad 1.877 * * *(0.648)$

$\begin{array}{llllll}70.259 & (123.828) & 0.486 * * & (0.202) & -0.700 & (0.572)\end{array}$

$277.220 * \quad(123.156) \quad 0.863 * * *(0.202) \quad 0.607 \quad(0.538)$

$267.248 * * \quad(125.140) \quad 1.367 * * *(0.207) \quad 0.575 \quad(0.572)$

$192.906 \quad(128.411) \quad 1.619 * * *(0.218) \quad 1.758 * * *(0.557)$

$26.411 \quad(120.056) \quad 1.334 * * *(0.200) \quad-0.107 \quad(0.566)$

$212.843 * \quad(128.068) \quad 1.932 * * *(0.221) \quad 2.943 * * *(0.537)$

$737.926 * * *(122.503) \quad 3.340 * * *(0.215) \quad 4.725 * * *(0.527)$

$462.315 * * *(125.682) \quad 1.650 * * *(0.221) \quad 3.970 * * *(0.523)$

$399.029 * * *(131.515) \quad 1.597 * * *(0.228) \quad 2.941 * * *(0.539)$

$376.795 * * * \quad(33.227) \quad 1.025 * * *(0.072) \quad 1.070 * * *(0.156)$

$368.649 * * \quad(152.766)-4.728 * * *(0.278)-7.482 * * *(0.663)$

\section{$19.965^{* * *}$}

$\begin{array}{cc}- & 2628.477^{* * * *} \\ - & 15079.751 \\ - & 12451.274\end{array}$

0.335

0.112

3334

0.261

11627 
which to compare the estimated parameter of the other two categories. These estimates should be interpreted as representing the marginal utility of choosing an informationonly strategy or online sales strategy over a pre-Internet strategy. Thus, a positive coefficient indicates that the greater the independent variable, the more likely the alternative will be chosen. Furthermore, three other multinomial logistic regression models have been estimated to investigate the regional impact on the online sales adoption of three types of goods that differ in terms of logistic intensity (table 6).

Table 6. Estimation results for online sales strategies, differentiated by logistic goods type (the reference category is pre-Internet strategy) ${ }^{\text {a }}$.

$\begin{array}{lll}\text { Mail goods } & \text { Parcel goods } & \text { Freight goods } \\ B(\mathrm{SE}) & B(\mathrm{SE}) & B(\mathrm{SE})\end{array}$

Regional hierarchy

Periphery

Intermediary zone

Core (Randstad)

Urban hierarchy

Small-sized cities

Medium-sized cities

Large-sized cities

Shopping center hierarchy

Small neighborhood/ convenience centers

City district/large neighborhood centers

City/village centers

Solitary urban locations

Peripheral/large-scale retail locations

$B(\mathrm{SE}) \quad B(\mathrm{SE})$

Retail category

Supermarkets

Delicatessen stores

Drug stores

Perfume and cosmetic stores

Ladies-wear stores

Family-wear stores

Men's fashion stores

Sport shops

Furniture stores

Toy stores

Computer stores

Book stores

0

$\begin{array}{llllll}0.263 & (0.225) & -0.081 & (0.153) & 0.437 & (0.416) \\ 0.498^{*} & (0.289) & 0.390 * * & (0.181) & 0.977 * * & (0.447)\end{array}$

CD shops

0

$\begin{array}{ll}0.564 * * * & (0.207) \\ 0.549 * & (0.325)\end{array}$

0

$0.533 * * *(0.139) \quad 0.513$

(0.359)

$0.715^{* * *}(0.238)$

$-0.493$

(0.542)

0

$\begin{array}{ll}0.878 * & (0.524) \\ 1.361 * * * & (0.472) \\ 1.790 * * * & (0.549) \\ 1.142 & (0.750)\end{array}$

0

0

$\begin{array}{llrr}0.052 & (0.307) & -0.414 & (0.665) \\ & & & \\ 0.648^{* *} & (0.260) & -0.199 & (0.544) \\ 0.372 & (0.293) & -0.223 & (0.689) \\ 0.693^{* *} & (0.322) & 0.890 & (0.652)\end{array}$

Size

Log (floor space) $\left(\mathrm{m}^{2}\right)$

Intercept

$\chi^{2}-2 \log$ likelihood intercept only

$-2 \log$ likelihood final

Pseudo Nagelkerke $R^{2}$ square $N$

\begin{tabular}{|c|c|c|c|c|}
\hline- & \multicolumn{2}{|c|}{ - } & \multicolumn{2}{|l|}{0} \\
\hline- & \multicolumn{2}{|c|}{-} & \multicolumn{2}{|c|}{$2.033 * * *(0.620)$} \\
\hline- & 0 & & \multicolumn{2}{|c|}{-} \\
\hline- & 0.730 & $(0.480)$ & \multicolumn{2}{|c|}{-} \\
\hline- & -1.823 & $(0.372)$ & \multicolumn{2}{|c|}{-} \\
\hline- & -0.456 & $(0.324)$ & \multicolumn{2}{|c|}{-} \\
\hline- & -0.501 & $(0.375)$ & \multicolumn{2}{|c|}{-} \\
\hline- & 0.777 & $(0.360)$ & \multicolumn{2}{|c|}{-} \\
\hline- & \multicolumn{2}{|c|}{-} & \multirow{2}{*}{\multicolumn{2}{|c|}{$0.072{ }_{-}^{(0.579)}$}} \\
\hline- & 1.833 & $(0.314)$ & & \\
\hline- & 3.610 & $(0.297)$ & \multicolumn{2}{|c|}{-} \\
\hline 0 & \multicolumn{2}{|c|}{-} & \multicolumn{2}{|c|}{-} \\
\hline$-0.977 * * *(0.192)$ & \multicolumn{2}{|c|}{-} & \multicolumn{2}{|c|}{-} \\
\hline $2.240 * * *(0.295)$ & \multicolumn{2}{|c|}{$0.709 * * *(0.228)$} & -0.526 & $(0.451)$ \\
\hline$-6.660 * * *(0.782)$ & -5.702 & $(0.572)$ & \multicolumn{2}{|c|}{$-3.499 * * *(1.270)$} \\
\hline $155.592 * * *$ & \multirow{2}{*}{\multicolumn{2}{|c|}{$\begin{array}{l}1798.238 * * * \\
9886.779\end{array}$}} & \multicolumn{2}{|c|}{$220.765^{* * *}$} \\
\hline 1853.159 & & & \multicolumn{2}{|c|}{2759.623} \\
\hline 1697.557 & \multicolumn{2}{|c|}{8088.541} & \multicolumn{2}{|c|}{2538.858} \\
\hline 0.166 & \multicolumn{2}{|c|}{0.252} & \multicolumn{2}{|c|}{0.137} \\
\hline 997 & \multicolumn{2}{|c|}{8678} & \multicolumn{2}{|l|}{1952} \\
\hline
\end{tabular}

a The estimation results for information-only strategies are not shown in this table.

$* p<0.10 ; * * p<0.05 ; * * * p<0.01$. 


\subsubsection{Shopping center hierarchy (hypotheses la to $2 b$ )}

There is no significant difference in the time of Internet adoption between independent retailers in city and village centers and their counterparts at shopping centers lower in the hierarchy (see model 1, table 5). As such, hypothesis 1a is not supported by our data. However, independents in city and village centers do have a higher probability of following an information-only and, even more so, an online sales strategy than their counterparts in city district, neighborhood, and convenience centers (see model 2, table 5). This is in line with hypothesis $1 b$.

According to hypothesis $2 \mathrm{a}$ and $2 \mathrm{~b}$, there is no significant difference in the time of adoption and the probability of adopting an Internet strategy among independent retailers in city or village centers, solitary urban independents, and independents in peripheral or large-scale retail locations. Hypothesis 2 a needs to be rejected, as independent retailers in peripheral and large-scale retail locations registered domain names much earlier than their counterparts in central and solitary urban locations. Hypothesis $2 \mathrm{~b}$ largely holds, as independent retailers in peripheral or large-scale retail locations, in city and village centers, and in solitary urban locations have about the same probability of following an online sales strategy (given the overlap in the value ranges in model 2). However, for the adoption of an information-only strategy there are significant differences between solitary urban retailers and their counterparts at the other two localities, as the former is less likely to adopt this strategy.

\subsubsection{Urban hierarchy (hypotheses $3 a$ and $3 b$ )}

With regard to the urban hierarchy we assumed that the time (hypothesis 3a) and the probability (hypothesis $3 \mathrm{~b}$ ) of Internet adoption by shops positively depends on the size of the city in which a shop is located. Results indicate that independent retailers located in large(r) cities were the first to register a domain name. They also have a higher likelihood of choosing an Internet strategy over a pre-Internet strategy, as compared with independents in small cities (see table 5). This substantiates hypotheses $3 \mathrm{a}$ and $3 \mathrm{~b}$.

\subsubsection{Regional hierarchy (hypotheses 4 a to $5 b$ )}

On the regional level we also assumed a spatial pattern in the diffusion of Internet adoption by independent retailers: independents in the core region (Randstad) are more likely to have registered an Internet domain earlier (hypothesis 4a) and to have a higher probability of Internet strategy adoption than their counterparts in less urbanized areas (hypothesis 4b). Hypothesis 4a is supported by our data, as independents in the core region registered their domain names earliest, followed by their counterparts in the intermediary zone (see model 1, table 5). Furthermore, independent retailers in peripheral areas have a lower probability of adopting an information-only strategy, as compared with independents in the intermediary and the core region. In addition, independents in the core region are more likely to follow an online strategy than their counterparts in the intermediary and peripheral regions (see model 2, table 5). Thus hypothesis $4 \mathrm{~b}$ is, by and large, also supported by our data.

We also expected the regional diffusion of online sales strategies to vary among retail categories depending on the logistic costs involved. First, we assumed that independents in the periphery that sell goods that are distributed by mail or parcel services are more likely to follow an online sales strategy than their counterparts in the core area (hypothesis 5a). Second, independent retailers in the core region that sell freight goods are more likely to adopt an online sales strategy than independents in the periphery (hypothesis 5b). To test these hypotheses, separate multinomial logistic regression models were estimated, one for each type of logistical good (see table 6). Note that the estimation results for information-only strategies are not shown in this table, as hypotheses $5 \mathrm{a}$ and $5 \mathrm{~b}$ concern only online sales strategies. 
The results of these additional analyses show that, for all three types of logistical goods, independent retailers in the core region have the highest probability of adopting an online sales strategy over a pre-Internet strategy. Despite the fact that the price of postal and parcel services is independent of distance in the Netherlands, the probability of online sales adoption is nevertheless highest among the independents in the core region. As such, hypothesis $5 \mathrm{a}$ needs to be rejected, while hypothesis $5 \mathrm{~b}$ is supported.

\subsubsection{Control variables: product and size}

We close this section with a brief description of the results for our two control variables in the models in table 5. As expected, independent retailers selling search goods have been on the Internet for a longer period and have a higher probability of choosing an informationonly or online sales strategy over no website than do independents selling experience of convenience goods. Furthermore, in general, independent retailers selling experience goods have a lower probability of adopting an online sales strategy than independents selling convenience goods. Concerning organization size, results indicate that the larger the floor space of independent retailers, the higher the probability that they registered a domain name early and that they follow an information-only or online sales strategy. These outcomes are in accordance with the findings of other empirical studies mentioned in the preceding discussion.

One should note that we also conducted two analyses in which we investigated the explanatory value of spatial variables without accounting for organizational variables. In these models - not included in this paper - the spatial outcomes were somewhat less clear-cut (mainly the results of the shopping center hierarchy). This can be explained by the fact that retail categories are not equally distributed among the types of shopping locations. Thus, to avoid composition effects when studying the geographical diffusion of retail Internet adoption, one should always account for organizational variables.

\section{Conclusions}

In this paper we investigated the geographical diffusion of Internet adoption among approximately 12000 independent retailers in the Netherlands. Results indicate that independents in city or village centers and peripheral or large-scale retail locations are more likely to follow an information-only or online sales strategy than their counterparts in centers at the bottom of the shopping center hierarchy. At the urban level a hierarchical diffusion pattern is also visible. Independents in large( $\mathrm{r}$ ) cities were online earlier and have a higher probability to adopt an Internet strategy than their counterparts in small(er) cities. At the regional level the likelihood of adopting an information-only or online sales strategy is higher for independent retailers in the core region (Randstad) than for independents in the periphery. Thus, agglomeration economies matter for retail Internet adoption at the level of shopping centers, cities, and regions.

As the rapid expansion of online sales in the Netherlands is expected to continue in the future (see Thuiswinkel.org, 2006), we predict that independent retailers in rural areas (in the periphery) will be most adversely affected by b2c e-commerce. Studies concerning the spatial diffusion of online shopping in the Netherlands revealed that consumers in rural areas - although having a lower probability of shopping onlineshop most frequently online and are most likely to substitute in-store shopping with online shopping (Farag et al, 2006; Weltevreden, 2007a). Given the fact that the probability of adopting an Internet strategy is lower in smaller cities and in peripheral regions, we expect independents at these localities to become the most likely victims of the further growth of b2c e-commerce in the Netherlands.

Regarding the importance of geography for understanding Internet adoption by (independent) retailers, progress in future research lies in two areas. First, given the 
exceptional retail and transport structure in the Netherlands, the outcomes presented in this paper do not necessarily apply to other developed countries. In other developed countries, such as France or the USA, with more spread-out populations, more out-oftown and large-scale retail developments, and a different transport structure (more car use), the spatial pattern of Internet adoption by retailers may be different. As such, future research should try to conduct similar studies in other countries or to feature a comparison among countries.

Second, studying the adoption of Internet strategies does not provide insights into the success of those strategies. For example, adopting an online sales strategy does not necessarily imply that incumbent retailers are successful in selling online (Weltevreden, 2007b). As such, future research should analyze the effects of adopting a certain Internet strategy on the performance of retailers at different shopping locations. This will further enhance our understanding of the impacts of b2c e-commerce on retailing and urban form.

Acknowledgements. We are most grateful to Marloes Krol for her assistance in collecting the domain name data. Furthermore, we would like to thank Marnix Breedijk and Niels van Diepen for making the maps. Finally, we would like to thank Ron Boschma and the three anonymous reviewers for their valuable comments on earlier drafts of this paper.

\section{References}

Anderson W P, Chatterjee L, Lakshmanan T R, 2003, "E-commerce, transportation, and economic geography" Growth and Change $34415-432$

Berry B J L, 1967 Geography of Market Centers and Retail Distribution (Prentice-Hall, Englewood Cliffs, NJ)

Borchert J G, 1998, "Spatial dynamics of retail structure and the venerable retail hierarchy" GeoJournal 45327 - 336

Boschma R A, Weltevreden J W J, forthcoming, "An evolutionary perspective on Internet adoption by retailers in the Netherlands" Environment and Planning $A$

Brown L A, 1981 Innovation Diffusion: A New Perspective (Methuen, London)

Burt S, Sparks W, 2003, "E-commerce and the retail process: a review" Journal of Retailing and Consumer Services $10275-286$

Christaller W, 1933 Central Places in Southern Germany (Prentice-Hall, Englewood Cliffs, NJ)

Copeland M T, 1923, "Relation of consumers' buying habits marketing methods" Harvard Business Review $1282-289$

Currah A, 2002, "Behind the web store: the organisational and spatial evolution of multichannel retailing in Toronto" Environment and Planning A 341411 - 1441

Dieleman F M, Dijst M, Burghouwt G, 2002, "Urban form and travel behavior: micro-level household attributes and residential context" Urban Studies 39507 - 527

Doherty N F, Ellis-Chadwick F, 2006, "New perspectives in Internet retailing: a review and strategic critique of the field" International Journal of Retail and Distribution Management 34411 - 428

Ellis-Chadwick F, Doherty N F, Hart C A, 2002, "Signs of change? A longitudinal study of Internet adoption in the UK retail sector" Journal of Retailing and Consumer Services 971 -80

Eurostat, 2006 Population Figures 2006 http://ec.europa.eu/eurostat/

Evers D, 2002, "The rise (and fall?) of national retail planning" Journal of Economic and Social Geography (TESG) $93107-113$

Farag S, Weltevreden J W J, van Rietbergen T, Dijst M, van Oort F G, 2006, "E-shopping in the Netherlands: does geography matter?" Environment and Planning B: Planning and Design $3359-74$

Farag S, Schwanen T, Dijst M, Faber J, 2007, "Shopping online and/or in-store? A structural equation model of the relationships between e-shopping and in-store shopping" Transportation Research A 41125 - 141

Foreman C, Goldfarb A, Greenstein S, 2005a, "How did location affect adoption of the commercial Internet? Global village vs urban leadership?" Journal of Urban Economics 58389 - 420

Foreman C, Goldfarb A, Greenstein S, 2005b, "Geographic location and the diffusion of Internet technology" Electronic Commerce Research and Applications 41 - 13

Guy C M, 1994 The Retail Development Process: Location, Property, and Planning (Routledge, London)

Heise Online, 2004, "Google findet nur 61 Prozent der .de-Domains" [Google finds only 61 percent of the .de domains], http://www.heise.de/newsticker/meldung/54151 
Klein L R, 1998, "Evaluating the potential of interactive media through a new lens: search versus experience goods" Journal of Business Research 41 195-203

Kolko J, 2000, "The death of cities? The death of distance? Evidence from the geography of commercial Internet usage", in The Internet Upheaval Eds I Vogelsang, B M Compaine (MIT Press, Cambridge, MA) pp $73-98$

Krizek K, Li Y, Handy S L, 2005, "Spatial attributes and patterns of use in household-related information and communications technology activity" Transportation Research Record number 1926, $252-259$

Locatus, 2004 Locatus Database Beschrijving [Locatus' database description] (Locatus, Woerden)

Morganosky M A, 1997, "Retailing and the Internet: a perspective on the top 100 US retailers" International Journal of Retail and Distribution Management 25372 - 377

Moss M L, 1998, "Technology and cities" Cityscape 3 107-127

Murphy A J, 2003, "(Re)solving space and time: fulfillment issues in online grocery retailing" Environment and Planning A $351173-1200$

Nelson P J, 1970, "Information and consumer behavior" Journal of Political Economy 78 311 - 329

NRW, 2005 Register van Planmatig Ontwikkelde Winkelcentra in Nederland [Guide of planned shopping centers in the Netherlands], Nederlandse Road van Winkelcentra, Utrecht

Peterson R A, Balasubramanian S, Bronnenberg B J, 1997, "Exploring the implications of the Internet for consumer marketing" Journal of the Academy of Marketing Science 25329 - 346

Pred A, 1977 City-systems in Advanced Economies (Hutchinson, London)

Ren F, Kwan M-P, 2006, "Does access to shopping opportunities affect e-shopping? A study in Columbus (Ohio, USA)", paper presented at the Second Specialist Meeting on ICT, Everyday Life and Urban Change, 9 - 12 November, Bergen, ftp://ftp.geog.uu.nl/pub/papers_bergen/ Ren\%20\&\%20Kwan\%202006.pdf

Schwanen T, Dijst M, Dieleman F, 2004, "Policies for urban form and their impact on travel: the Netherlands experience" Urban Studies $41579-603$

Sinai T, Waldfogel J, 2004, "Geography and the Internet: is the Internet a substitute or a complement for cities? " Journal of Urban Economics 561 - 24

Spierings B, 2006, "The return of regulation in the shopping landscape? Reflecting on the persistent power of city centre preservation within shifting retail planning ideologies" Journal of Economic and Social Geography (TESG) $97602-609$

Steinfield C, De Wit D, Adelaar T, Bruins A, Fielt E, Hoefsloot M, Smit A, Bouwman H, 2001, "Pillars of virtual enterprise: leveraging physical assets in the new economy" Info 3 203-213

Thompson W R, 1968, "Internal and external factors in the development of urban economies", in Issues in Urban Economics Eds H S Perloff, L Wingo (Johns Hopkins Press, Baltimore, MD) pp $43-80$

Thuiswinkel.org, 2006, "Homeshopping in the Netherlands", http://222.thuiswinkel.org (in Dutch)

van Oort F G, 2004 Urban Growth and Innovation. Spatially Bounded Externalities in the Netherlands (Ashgate, Aldershot, Hants)

Visser E-J, Lanzendorf M, 2004, "Mobility and accessibility effects of b2c e-commerce: a literature review" Journal of Economic and Social Geography (TESG) $95189-205$

Weltevreden J W J, 2007a Winkelen in het Internettijdperk [Shopping in the Internet age] (Nai Uitgevers and Ruimtelijk Planbureau, Rotterdam)

Weltevreden J W J, 2007b, "Substitution or complementarity? How the Internet changes city centre shopping" Journal of Retailing and Consumer Services $14192-207$

Weltevreden J W J, Atzema O A L C, 2006, "Cyberspace meets high street: adoption of click-and-mortar strategies by retail outlets in city centers" Urban Geography 27 628-650

Weltevreden J W J, van Rietbergen T, 2007, "E-shopping versus city centre shopping: the role of perceived city centre attractiveness" Journal of Economic and Social Geography (TESG) $9868-85$

Weltevreden J W J, Atzema O A L C, Boschma R A, 2005, "The adoption of the Internet by retailers: a new typology of strategies" Journal of Urban Technology 12 59-87

Worzala E M, McCarthy A M, Dixon T, Marston A, 2002, "E-commerce and retail property in the UK and USA" Journal of Property Investment and Finance $20142-158$

Wrigley N, 1985 Categorical Data Analysis for Geographers and Environmental Scientists (Longman, London)

Wrigley N, Lowe M, Currah A, 2002, "Retailing and e-tailing” Urban Geography 23 180-197 
Conditions of use. This article may be downloaded from the E\&P website for personal research by members of subscribing organisations. This PDF may not be placed on any website (or other online distribution system) without permission of the publisher. 